\title{
Autonomous Photovoltaic Lighting System
}

\author{
Ahmed A. A. Hafez ${ }^{1}$ Daniel Montesions-Miracle ${ }^{2} \quad$ Antoni Sudria-Andreu $^{2}$ \\ ${ }^{1}$ Electrical Engineering Department, Faculty of Engineering, Assiut University, Assiut, Egypt, PO 71516 elhafez@aun.edu.eg \\ ${ }^{2}$ Centre d'Innovació Tecnològica en Convertidors Estàtics i Accionaments (CITCEA-UPC), Departament d'Enginyeria Elèctrica, \\ Universitat Politècnica de Catalunya.ETS d'Enginyeria Industrial de Barcelona, Av. Diagonal, 647, Pl. 2. 08028 Barcelona, Spain
}

\begin{abstract}
This paper introduces a comparison between the conventional and Photovoltaic (PV) lighting systems. A simple sizing procedure for a PV stand-alone system was advised. The paper also proposes a novel PV lighting system. The proposed system is simple, compact and reliable. The system operation was investigated by thoroughly mathematical and simulation work.
\end{abstract}

\section{INTRODUCTION}

Traditionally the power required for illuminating the intracities roads is imported from the utility grid. This grid lighting system has a number of disadvantages, such as [1-7]:

i. It increases the consumption/depletion of fossil fuels and hence energy prices.

ii. It adds to the environment pollution through the waste products from the power plant [8].

iii. It worsens the grid stability, and mandates the applications of costly power factor/static var compensators, as most of the street lamps have very low lag power factors $(0.5-0.65)$.

iv. The lighting grid system generally is unreliable, as a fault in/near a single pole may disable the entire road [9-11].

To eradicate these disadvantages, a move toward a lighting system based on the PV is necessary. The PV lighting system has a number of advantages, such as:

i. Energy independence and environmental compatibility, the fuel is free, and no noise or pollution is created from operating the PV system [1-3].

ii. The PV lighting system is decoupled to the grid, which enhance the grid stability [11].

iii. In the PV lighting system, each pole is fully decoupled from the remaining poles. Thus a fault in pole or a group of poles has minimal impact on the entire lighting system, which boosts the safety and the reliability.

This paper introduces a comparison between the grid and the PV lighting system. Also, it proposes a novel PV lighting system.

The paper is organized as follows: Section II introduces a comparison between lighting systems supplied from the grid and the PV modules. The comparison includes a simple sizing procedure for a stand-alone PV system. An innovative PV lighting system was advised in Section III. This Section includes also a detailed modeling for the different components of the proposed system. Section VI introduces the proposed control technique. The simulation results over the full operating cycle of the advised lighting system are given in Section V.

\section{COST COMPARISON}

In order to assess the economic visibility of the PV lighting system, a cost comparison between conventional and PV lighting systems is carried out for one kilometer $(\mathrm{km})$ of the road connecting Aswan and Alexandria in Egypt. This road is extended in southern desert in Egypt for around 1,000 $\mathrm{km}$. Egypt in general has nearly sunny climate over the entire year, particularly in the southern desert. Moreover, there are no natural or artificial obstacles that could limit the falling irradiation on the prospect PV system in this road.

\section{A. Conventional system}

Different types of lamps are utilized for lighting public avenues and roads in Egypt. However, Halogen Sodium (400W) and Mercury vapor (250W) are widely used, particularly in lighting the intra-cities roads. Recently, there is a move toward replacing these lamps by the Compact Fluoresce Lamp (CFL) (105W) [12].

Usually highways in Egypt are illuminated from the dusk until dawn; thus the street lamp is operating for around 10 hours. The power consumptions of the Halogen, Sodium and CFL lamps in kiloWatt-hour (kWh) for 10 hour operation per day per 20 years are given in Fig. 1. The time span of 20 years is considered in producing Fig. 1 to allow comparison with the PV systems. As the reported average life-cycle of a PV system varies from 20 to 25 years [1-3]. It is worth to mention that some components in the PV system such as batteries and converters have reduced life cycle than the PV module; however the cost of these components represents around $(10 \%$ to $15 \%)$ of the entire system cost [13-15]. 


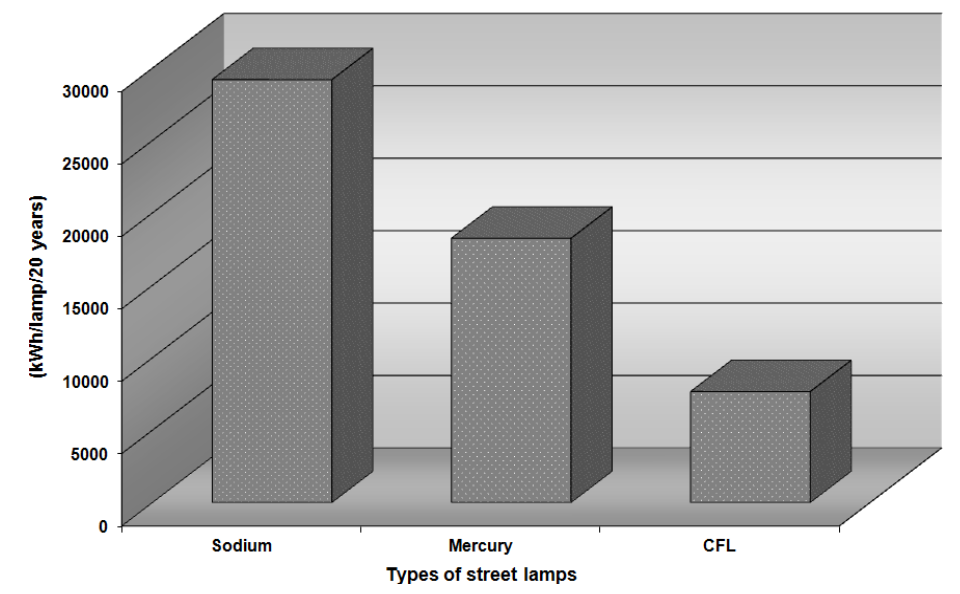

Fig. 1. Power consumption of different types of street lamps in 20 year per one lamp

Fig. 1 shows that the CFL consumes around $74 \%$ and $49 \%$ less than Sodium and Mercury lamps respectively. This energy saving may overwhelm the demerits of CFL in polluting the grid with harmonics, particularly CFL with conventional ballast [16].

According to the Egyptian code [17], the number of poles per $\mathrm{km}$ varies from 30 to 35 . An average value of 32 poles per $\mathrm{km}$ is taken in this study.

The power consumptions of one- $\mathrm{km}$ in the road under concern in kWh per 20 years for Sodium, Mercury and CFL lamps are given in Fig. 2 for 10 hour operation.

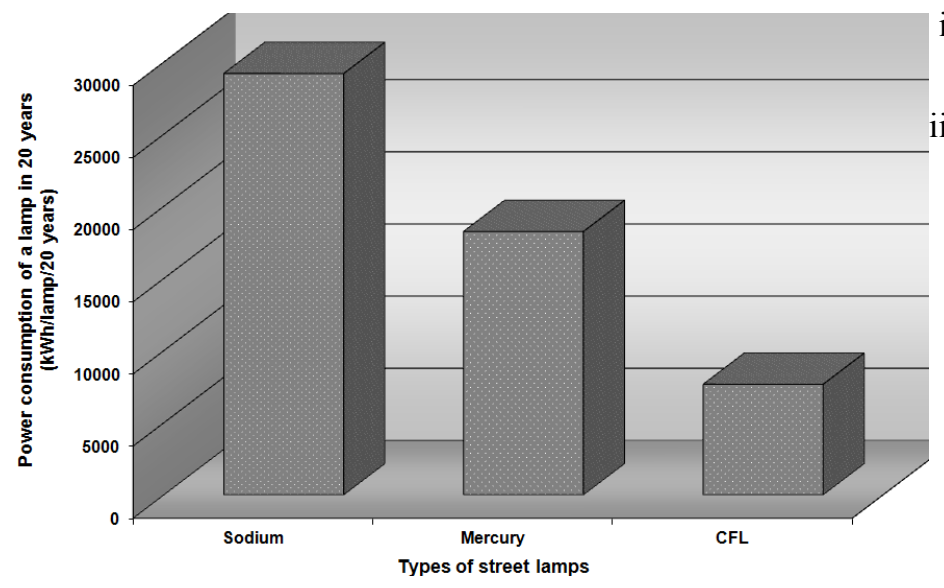

Fig. 2. Power consumption of different lamps in one-km in 20-year

Fig. 2 indicates that the required power for illuminating a kilometer in a road over 20 years is around 934.4MWh, 584MWh, and 245.280MWh for Sodium, Mercury and CFL lamps respectively.

The costs of illuminating a distance of one kilometer of the road under concern in 20 years calculated based on the tariff of $0.1 \mathrm{US} \$ / \mathrm{kWh}$ for Sodium, Mercury and CFL are given in Fig. 3. The tariff of $0.1 \mathrm{US} \$ / \mathrm{kWh}$ is taken as an average over the 20 years. However, the cost of $0.1 \mathrm{US} \$ / \mathrm{kWh}$ is considered to be underestimation for prices of electricity generated by fossil fuels in the future [17].

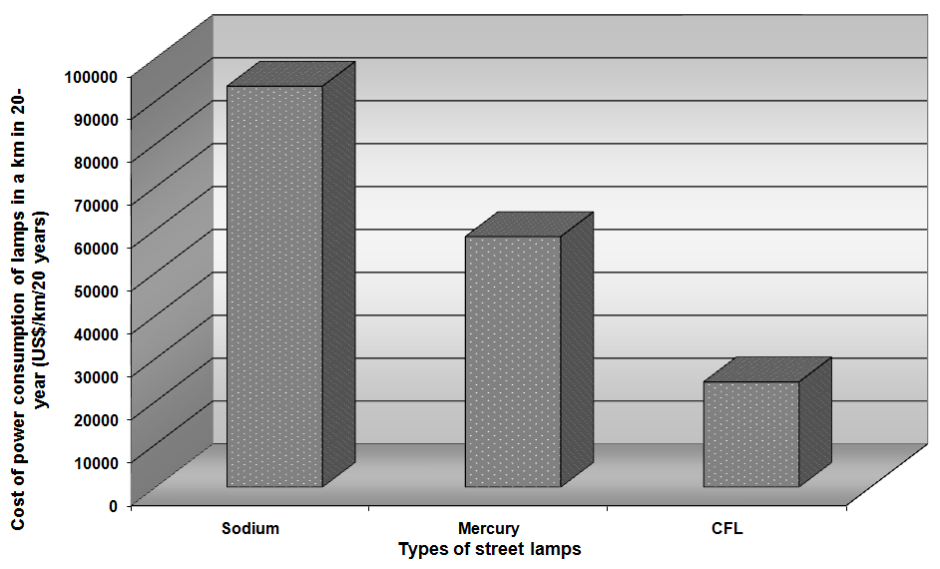

Fig. 3. Cost of power consumption of different lamps in one-km in 20year

The cost of illuminating a kilometer in the road under concern for 20 years is $93.4 \mathrm{kUS} \$$ for Sodium lamp as shown in Fig. 3; therefore, for a road extending up to $1000 \mathrm{~km}$, the cost will be around 100 million US\$, and this is significant, particularly for developing countries.

In developing Fig. 3 the following are ignored:

i. The impact of electricity production in polluting the surrounding environment and distorting the ecosystem in the nearby rivers/lakes

ii. The cost due to the consequences of losing lighting system in a busy traffic and condensed roads on the economic.

iii. The costs of poles, transformers, transmission lines, lamps and protective and auxiliary components

\section{B. PV system}

In order to estimate the cost of PV lighting system, the designing process of the system has to be carried out. Generally, the design of a robust PV stand-alone system is iterative procedure that entails a number of steps as shown in Fig. 4.

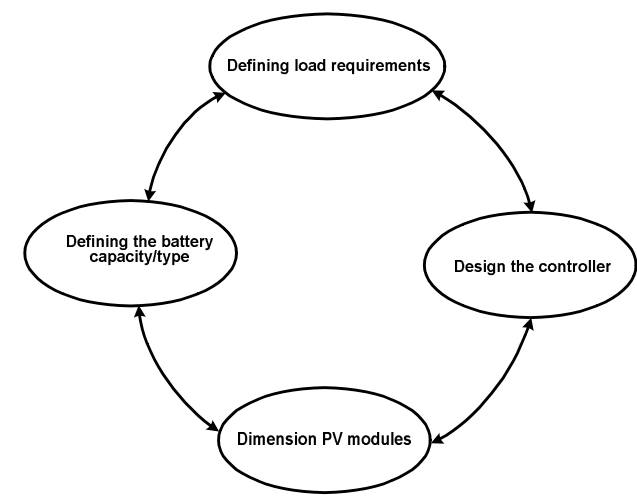

Fig. 4. Flowchart for stand-alone PV system design 


\section{i. $\quad$ Load requirements}

The load is the key element in sizing a stand-alone PV system; therefore it desirable to enhance the efficiency of the load. For the system under concern, it could be realized by selecting more efficient light sources, improved luminaries design, adequate control of operating time/level and better aiming and distribution of the light. Commonly, the load is expressed in terms of ampere-hour (Ah) that is the product of the duration of the load operation and the load current.

For a PV lighting system, the duration of the light availability varies according to the geographical location. The number of night hours could be estimated for an arbitrary site by [18],

$$
\mathrm{H}_{\mathrm{N}}=2\left[12-\frac{1}{15} \cos ^{-1}\left(\frac{-\tan (\mathrm{L})}{\tan \left(\sin ^{-1}(0.397 * \cos (0.9586(\mathrm{~N}-173)))\right)}\right)\right]
$$

where $\mathrm{L}$ is the latitude in degree, $\mathrm{N}$ Julian day number (1365). For Egypt and countries near equator, equal length for the day and the night could be fair assumption.

The average daily lighting load is usually calculated for critical design month, where maximum load operation period occurs.

For the system under concern, the load requirements could be determined as follow; the $105 \mathrm{~W}$ lamp will be used at voltage of $12 \mathrm{VDC}$. This is battery voltage, which the system operates at if the battery and load interfacing converter fails. The load current accordingly is $8.75 \mathrm{~A}$. As mentioned before that Egypt approximately has equal day and night period throughout the year. Thus, for a lighting system operates between dusk and dawn, the average operating time is 10 hours; and hence the average daily lighting load is $87.5 \mathrm{Ah}$.

\section{ii. Battery requirements}

Battery size is determined according the maximum allowable discharge depth, de-rating factor for low temperatures and the desired length of battery stand-alone mode. Deep discharge cycle batteries are commonly used in PV lighting system. The capacity of the battery in the lighting system could be estimated from the following empirical formula [18],

$$
\mathrm{Q}=\frac{\text { length of stand-alone mode(days)* Average daily load (Ah) }}{\text { Discharge depth* low temperature derating factor }}
$$

The low temperature deteriorates the performance of the battery. This is attributed to the electrochemical process. The phenomenon of low temperature is quite obvious in the Lead-Acid batteries. Their capacities drop by around $20 \%$ for the temperature drops from $25^{\circ} \mathrm{C}$ to $0^{\circ} \mathrm{C}$ [13-16].

For the proposed PV lighting system, Egypt is a sunny climate throughout the year particularly in the desert where the road under concern is located. However, the stand-alone battery mode is assumed to be 2 days. The discharge depth is
$80 \%$, and the derating factor due to temperature deviation and aging is assumed to be 0.8 due to desert climate; thus the capacity of the required battery according to (2) is $27.3 \mathrm{Ah}$.

\section{iii. $\quad$ PV arrangement}

The size of the PV modules is commonly estimated based on ability of the system of proving adequate energy to the average daily load for lowest solar insolation levels. The losses in the different parts of the system as well as the impact of temperature rise on the output of the PV module should be considered during the sizing.

The size of PV modules is usually selected according to the solar radiation for the critical design month, where sun insolation is at lowest. The size of the PV could be determined by the following empirical relation [18],

PV system rating $=\frac{\text { daily load in Ah* Average daily load }(\mathrm{Ah})}{\text { System efficiency } * \text { Derating Factor }}$

The derating factor accounts for reduction in PV output due to temperature, aging and degradation.

For the proposed system, the average daily load is $87.5 \mathrm{Ah}$; and the losses are assumed to be $15 \%$; derating factor is assumed to 0.7 ; therefore the size of PV system is around $150 \mathrm{~W}$ for each pole.

The cost of 150W PV module is around 600\$ [19]. The cost of batteries, converter and accessories is assumed 50\% of PV module cost [4], to consider their reduced life cycle and the need for their replacement up to four times during the course of system operation.

The cost of illuminating one kilometer in a road for the grid and the PV lighting systems is shown in Fig. 5.For the grid lighting system, the cost is calculated by multiplying the consumed power of the CFL lamps in a kilometer in the road under concern for 20 years by the tariff of $0.1 \mathrm{US} \$ / \mathrm{kWh}$. For the PV lighting system, the cost is computed by multiplying the cost of the PV system for one pole in the number of poles in a kilometer.

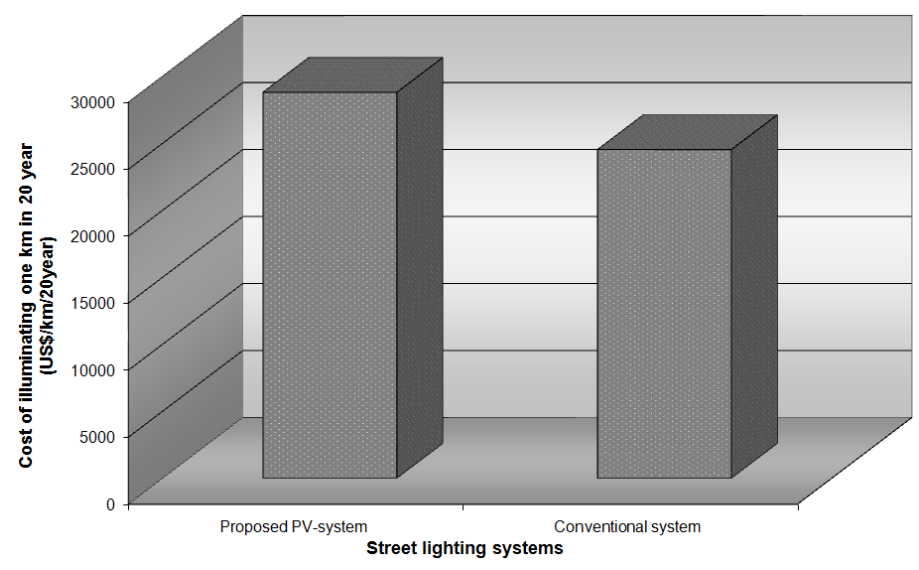

Fig. 5: Cost of illuminating one-kilometer for conventional and PV lighting systems 
Fig. 5 shows that the cost of PV system is around $16 \%$ higher than conventional systems. However the tariff of $0.1 \$ / \mathrm{kWh}$ used for generating Fig. 5 is underestimation for energy price over the next decades. This as mentioned before is attributed to the steady increase in the price of fossil and the depletion of its reserve.

\section{Proposed PV LINGHTing System}

Schematic diagram of the proposed system is shown in Fig. 6,

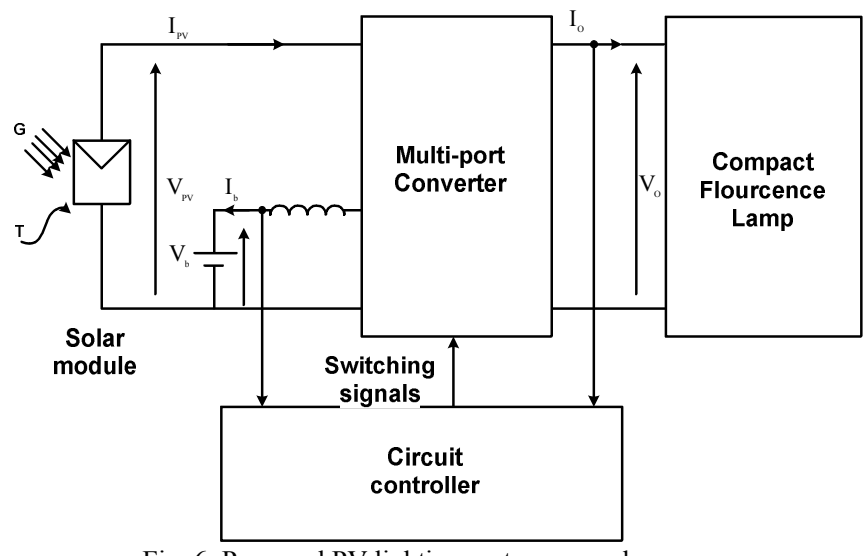

Fig. 6. Proposed PV lighting system per pole

The proposed PV lighting system as shown in Fig. 6 consists of a PV module of $150 \mathrm{~W}$, Multi-Port Converter (MPC), battery, and DC lamp of $105 \mathrm{~W}$. The detailed design of each component is given in the following.

\section{PV Generator}

Different models are proposed for stimulating a PV cell, these models vary in accuracy and complexity. In the proposed system, moderate model is advised for depicting the static and dynamic performance of the PV cell. The PV cell is modeled as a solar irradiation and temperature dependent current source $\mathrm{I}_{\mathrm{ph}}$ in parallel with diode. This combination is in series with a series resistance $R_{s}[20]$. This model of the PV has the advantages of accuracy, robustness and simplicity.

Basically the PV cells are grouped in series to deliver a reasonable voltage/power, these structures are themed modules. The module has an equivalent circuit similar to that of the cell.

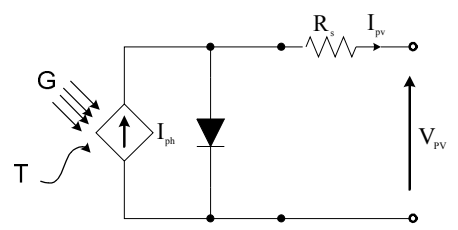

Fig. 7. Equivalent circuit of PV cell/module

The relation between the terminal current $I_{p v}$ and voltage $\mathrm{V}_{\mathrm{pv}}$ of a PV module is expressed in terms of the terminal voltage $\mathrm{V}_{\mathrm{pv}}$, short-circuit current $\mathrm{I}_{\mathrm{sc}}$ and open-circuit voltage $\mathrm{V}_{\mathrm{oc}}$ of the module by,

$$
I_{\mathrm{pv}}=\mathrm{I}_{\mathrm{sc}}\left(1-\exp \left(\frac{\mathrm{V}_{\mathrm{pv}}-\mathrm{V}_{\mathrm{oc}}+\mathrm{I}_{\mathrm{pv}} \mathrm{R}_{\mathrm{s}}}{\mathrm{V}_{\mathrm{th}}}\right)\right)
$$

where $\mathrm{R}_{\mathrm{s}}$ is series resistance ; $\mathrm{V}_{\text {th }}=\mathrm{nN}_{\mathrm{s}} \mathrm{kT} / \mathrm{q}$ is thermal voltage of the module; $\mathrm{n}, \mathrm{N}_{\mathrm{s}}, \mathrm{K}, \mathrm{T}$ and $\mathrm{q}$ are ideality factor, number of cells in series, Boltzmann constant and electron charge respectively. The short-circuit current $\mathrm{I}_{\mathrm{sc}}$ and open-circuit voltage $\mathrm{V}_{\mathrm{oc}}$ are commonly supplied by the manufacturers at standard conditions.

The PV generator in the proposed PV lighting system is composed of two series connected BP $75 \mathrm{~W}$ modules. The parameters of BP $75 \mathrm{~W}$ module are given in Table 1 [21]. Implementing the PV generator from two series connected PV module ensures that the input voltage is higher than battery (output) voltage; thus the MPC operates the PV generator at maximum power point irrespective to irradiation level.

TABLE I

PARAMETERS OF BP $75 \mathrm{~W}$ SOLAR MODULE AT $25^{\circ} \mathrm{C}$ AND $1000 \mathrm{~W}^{2} \mathrm{M}^{-2}[21]$

\begin{tabular}{|l|l|}
\hline Short circuit current & $4.86 \mathrm{~A}$ \\
\hline Open circuit voltage & $21.6 \mathrm{~V}$ \\
\hline Current at MPP & $4.36 \mathrm{~A}$ \\
\hline Voltage at MPP & $17.2 \mathrm{~V}$ \\
\hline Maximum power & $75 \mathrm{~W}$ \\
\hline Voltage coefficient & $-0.08 \mathrm{~V} / \mathrm{C}^{0}$ \\
\hline Current coefficient & $0.65 \mathrm{~mA} / \mathrm{C}^{\circ}$ \\
\hline Dimensions & $836 \times 670 \mathrm{~mm}$ \\
\hline
\end{tabular}

\section{Multi-Port Converter}

The MPC is a novel topology that derived from buck and boost topologies, Fig. 8. This circuit allows bidirectional power flow regarding the battery, and unidirectional power flow regarding the PV module and the load.

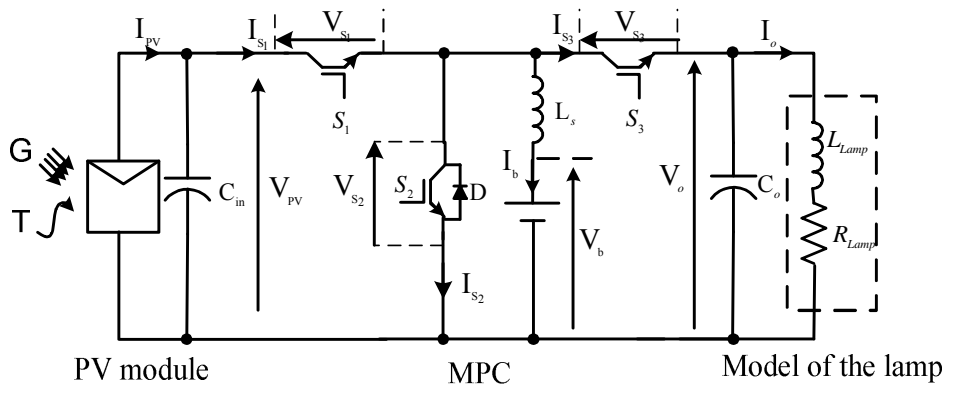

Fig. 8. PV generator, MPC and lamp

For the application under concern, the power of the PV generator is transferred to battery, then from battery to the load through MPC. The MPC can, however, allow dual input/output modes. For example, the PV generator supplies the battery and load simultaneously in dual output mode. Moreover, the load could be powered from the battery and PV generator simultaneously in dual input mode. 
Furthermore, the battery supplies the load, if the source is off.

The MPC ensures that the PV generator operates at maximum power point irrespective to solar irradiation and temperature. Also it could regulate either the load voltage or current.

The MPC consists of three switches and a diode $\mathrm{S}_{1}, \mathrm{~S}_{2}, \mathrm{~S}_{3}$ and D. For the application under concern, when $S_{1}$ is on, $S_{2}$ and $S_{3}$ are off and vice versa. The switch $S_{1}$ is normally operated with diode $\mathrm{D}$ to charge the battery during the day. They constitute a buck converter, while switches $\mathrm{S}_{2}$ and $\mathrm{S}_{3}$ resembles boost converter, and operate during the night to interface the battery to the lamp. The switching diagram of the MPC for the application under the concern is shown in Fig. 9

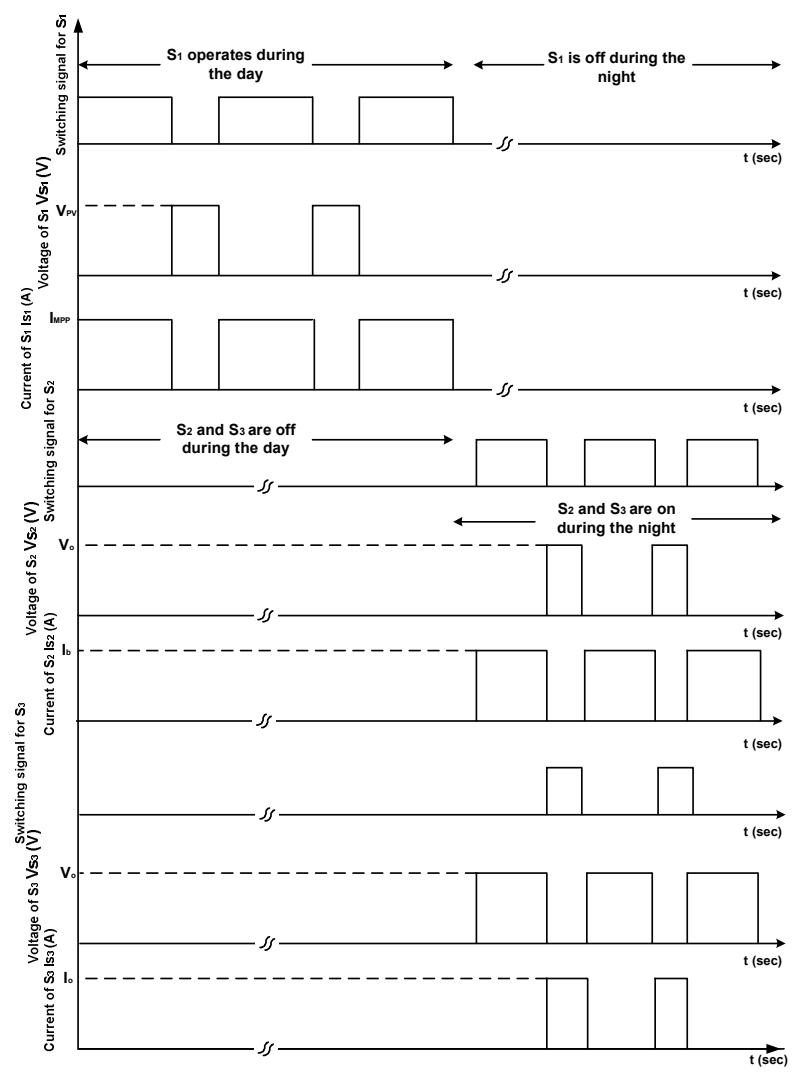

Fig. 9. Switching diagram for the MPC

\section{Battery}

The battery is the key component for a robust stand-alone PV system, due to its functionality in storing the power extracted from the PV module, operating the load at stable voltages and establishing suitable operating voltages to maximize the captured power from the PV module.

Recently, battery industry has reached a reasonable matured level; different types/capacities of batteries are commercially produced. These differ widely regarding design, performance characteristics and suitability to particular application. The Lead-Acid batteries are commonly deployed in PV applications due availability in different sizes, reduced cost and robust performance [12-15]. Among Lead-Acid batteries, Lead-Antimony type has the advantages of reduced cost, wide availability, good deep charge/discharge cycle, and withstanding high temperature. However Lead-Antimony batteries suffer from the water loss and requirement for albeit high maintenance rate, which can add to the cost of the system.

Due to the orbital motion of the earth, the duration of solar irradiance availability varies considerably according to the geographical locations. Thus, the battery capacity/size varies from site to site for a PV lighting system. However, for Egypt, almost there is a symmetry regarding the length of the day/night over the year. Thus, the batteries in the proposed PV lighting system are more likely not subjected to irregular charging/discharging pattern.

The battery is modeled here as a controlled voltage source in series with a resistor $\mathrm{R}_{\mathrm{b}}$, Fig. 10; the resistor stands for the ohmic losses inside the battery and at the leads [15].

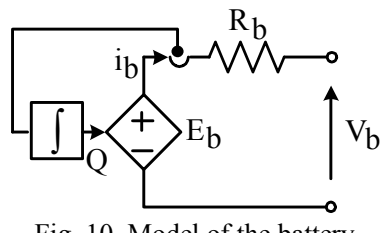

Fig. 10. Model of the battery

The resistance $R_{b}$ is assumed to remain constant, the voltage $\mathrm{E}_{\mathrm{b}}$ is given by,

$$
\mathrm{E}_{\mathrm{p}}=\mathrm{E}_{\mathrm{o}}-\mathrm{V}_{\mathrm{r}} \frac{\mathrm{Q}}{\mathrm{Q}_{\mathrm{o}}}+\mathrm{V}_{\mathrm{e}} \exp -\frac{\mathrm{Q}_{\mathrm{o}}-\mathrm{Q}}{\mathrm{Q}_{\mathrm{e}}}
$$

where $E_{0}, V_{r}, V_{e}$ are open-circuit, polarization and exponential voltages respectively; $\mathrm{Q}, \mathrm{Q}_{\mathrm{o}}$, and $\mathrm{Q}_{\mathrm{e}}$, are current, rated and exponential capacities in terms of ampere-hour respectively.

To supply the required capacity for the system under concern, five Lead-Antimony batteries of 55Ah are connected in parallel, the nominal voltage of each battery is $12 \mathrm{~V}$. The battery consists of six-cell; the parameters of a battery cell are given in Table 2 .

TABLE 2

PARAMETERS OF UNIT IN A LEAD-ANTIMONY BATTERY [22]

\begin{tabular}{|l|l|}
\hline Nominal voltage & $2 \mathrm{~V}$ \\
\hline Rated capacity & $9.2 \mathrm{Ah}$ \\
\hline Internal resistance & $0.02 \Omega$ \\
\hline
\end{tabular}

\section{Lamp}

Due to the growing interest in PV applications, a number of lamps were emerged recently. These lamps operate from a DC source; they could be fitted in variety of applications as lighting. The lamp considered in this work is $105 \mathrm{~W}$ cool white CFL lamp. This lamp produces around 6800lumens 
and is modeled as a resistor and an inductor in series. A capacitor is added in parallel to maintain the output voltage constant [9-11]. The CFL lamp in the proposed PV lighting system operates from $120 \mathrm{~V}$ DC source.

\section{PROPOSED CONTROLLER}

For the application under concern, the MPC charges the battery through $\mathrm{S}_{1}$ and $\mathrm{D}$ during the availability of solar insolation, while the remaining switches are off. During the night, the battery powers the load through switches $S_{2}$ and $S_{3}$ while switch $\mathrm{S}_{1}$ is off. The MPC could be considered here as decoupled buck and boost converters. The buck converter charges the battery from the PV module, while the boost converter interfaces the battery and the load. Thus each converter could be controlled independently.

Variety of Maximum Power Point Tracking (MPPT) algorithms are reported in literature [23-25], these techniques vary according to complexity, cost, hardware implementation and availability. For the PV lighting system, a cheap and efficient MPPT has to be deployed. The incremental conductance MPPT has the advantages of availability and capability of tracking MPP under wide operating conditions of solar irradiance and temperature. The slope of powervoltage curve of a PV generator could be expressed by,

$$
\frac{\mathrm{dP}_{\mathrm{pv}}}{\mathrm{dV}_{\mathrm{pv}}}=\mathrm{I}_{\mathrm{pv}}+\mathrm{V}_{\mathrm{pv}} \frac{\mathrm{dI}_{\mathrm{pv}}}{\mathrm{dV}_{\mathrm{pv}}},
$$

The slope of power-voltage curve of a PV module, is positive on the left of MPP, negative on the right and zero at MPP. Thus the relation between the incremental and instantaneous conductance is given by,

$$
\begin{aligned}
& \frac{\Delta \mathrm{I}_{\mathrm{pv}}}{\Delta \mathrm{V}_{\mathrm{pv}}} \succ-\frac{\mathrm{I}_{\mathrm{pv}}}{\mathrm{V}_{\mathrm{pv}}}, \text { left MPP } \\
& \frac{\Delta \mathrm{I}_{\mathrm{pv}}}{\Delta \mathrm{V}_{\mathrm{pv}}}=-\frac{\mathrm{I}_{\mathrm{pv}}}{\mathrm{V}_{\mathrm{pv}}}, \text { at MPP, } \\
& \frac{\Delta \mathrm{I}_{\mathrm{pv}}}{\Delta \mathrm{V}_{\mathrm{pv}}} \prec-\frac{\mathrm{I}_{\mathrm{pv}}}{\mathrm{V}_{\mathrm{pv}}} \text {, right MPP }
\end{aligned}
$$

MPP is tracked by continuously comparing the incremental and instantaneous conductance and incrementing/decrementing the PV voltage/current. [25]. An innovative implementation for the incremental conductance is proposed in [24]. According to (5), the sum of the incremental and instantaneous conductance is equal to zero at MPP; therefore employing a sufficiently fast PI controller ensures that sum is settled at zero at different operating conditions of temperature and solar irradiance.

$$
E=\frac{\Delta \mathrm{I}_{\mathrm{pv}}}{\Delta \mathrm{V}_{\mathrm{pv}}}+\frac{\mathrm{I}_{\mathrm{pv}}}{\mathrm{V}_{\mathrm{pv}}},
$$

The bandwidth of this controller should be sufficient high to allow satisfactory tracking for solar irradiation [24]. The proposed incremental conductance could be implemented by a low cost DSP. The parameters of the PI controller tuned using the approach in [24] are given in Table 3.
TABLE 3

PARAMETERS OF PI CONTROLLER IN MOIDIFED INCEREMENTAL CONDUCTANCE [24]

\begin{tabular}{|l|l|}
\hline Gain & 500 \\
\hline Zero & $0.4 \mathrm{rad} / \mathrm{sec}$ \\
\hline
\end{tabular}

Placing the zero of the PI controller near to natural origin pole increases the bandwidth, while maintaining the stability and providing sufficient attenuation for the switching frequency ripples.

To prevent the overcharge or excessive discharge of the battery, its voltage is restricted within a band around the nominal value, $12 \mathrm{~V}$. The switch $\mathrm{S}_{1}$ will be opened, if the battery voltage exceeds the upper limit, $14.2 \mathrm{~V}$; whereas switches $S_{2}$ and $S_{3}$ are opened for lower limit violation, $11.1 \mathrm{~V}$.

During the load operation, the switches $\mathrm{S}_{2}$ and $\mathrm{S}_{3}$ are controlled so that the load voltage is maintained constant at $120 \mathrm{~V}$. Although a PI controller is used to regulate the load voltage, however, for the lighting load supplied through the battery an open loop control for the switches will be simple, inexpensive, reliable and sufficient.

The parameters of the PI controller used for regulating the lighting voltage load are tuned using pole-placement technique [26]. The parameters are given in Table 4.

TABLE 4

PARAMETERS OF PI CONTROLLER [BB]

\begin{tabular}{|l|l|}
\hline Gain & 0.02 \\
\hline Zero & $100 \mathrm{rad} / \mathrm{sec}$ \\
\hline
\end{tabular}

\section{RESUlTS AND DisCUSSIONS}

The following figures show the dynamic performance of the system during a complete operating cycle. The solar irradiance was stimulated to vary as half sinusoidal wave, its peak occurs at $12 \mathrm{O}^{\prime}$ clock; while the PV temperature is maintained constant at $25^{\circ} \mathrm{C}$. The $\mathrm{PV}$ generator current, voltage and power were shown in Fig. 11; while Fig. 12 illustrates battery voltage, current, load voltage and power over complete charging and discharging cycle. In Figs. 11 and 12 solar irradiation is assumed to be available over 12hours from 6 AM until 6 PM, while the lighting system operates over 10 hours from 7 PM until 5 AM . 

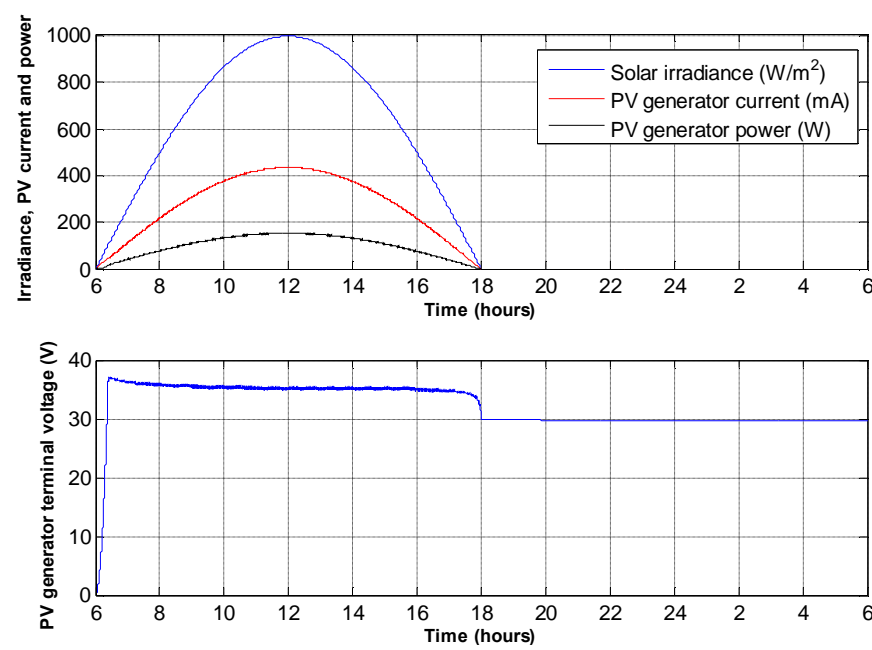

Fig. 11. Top graph: Solar irradiance (blue), PV generator power (red) and current (black), Bottom graph: PV generator terminal voltage over a full operating cycle and at $25^{\circ} \mathrm{C}$

Fig. 11 shows that the proposed MPPT forces the system to operate at MPP at varying irradiation. The PV generator current and power vary almost linearly with the solar irradiance; while the terminal voltage is nearly constant. This conclusion was reported in [24].

The PV generator terminal voltage has non zero value in the absence of solar irradiance. This is attributed to the characteristics of solar cell which resembles P-N junction. In the absence of solar irradiance, this $\mathrm{P}-\mathrm{N}$ junction is reserve based, thus there is potential gradient. The PV module usually consists of large number of series connected cells, 36 for the BP $75 \mathrm{~W}$. The sum of the reverse voltage of all these cells gives the non-zero value of the PV generator terminal voltage.
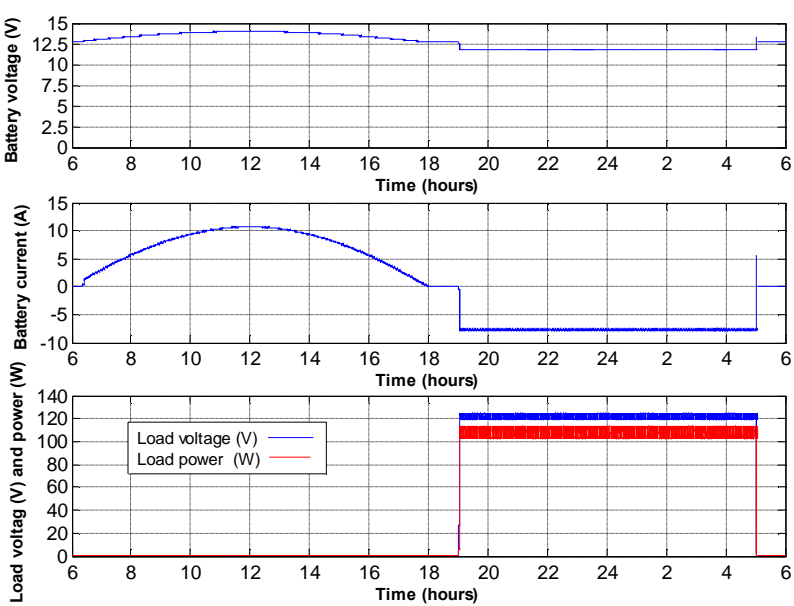

Fig. 12. Top graph: battery voltage (blue); Middle graph: battery current; Bottom graph: load power (blue) and voltage (red) over a full operating cycle and at $25^{\circ} \mathrm{C}$

Fig. 12 shows that the lighting operates from dusk (7PM) until dawn (5AM), which is more convenient for Egypt and countries near equator. Limiting the duration of PV lighting operation without comprising safety and reliability is a priority in stand-alone PV systems. There are two hours over the operating cycle, where all switches of MPC are off.

Fig. 12 shows that the battery voltage is within the allowed limits. The boost stage of the MPC increases the load voltage to a level, which is suitable for DC or AC lighting structures.

The MPC as shown in Figs. 11 and 12 have the advantages of providing continuous, ripple-free, battery and load currents. However, the input current of PV generator is discontinuous and a filter capacitor has to be deployed.

\section{CONCLUSION}

The following conclusions could be drawn:

1. The CFL is proven to be future trendsetter for the lighting industry due to the reduced power consumption and extended lifetime; however this lamp is albeit expensive.

2. The cost of PV lighting system is slightly higher than their conventional counterparts; however the merits of reliability, sustainability and environmentally compatibility overwhelm the evaluated cost.

3. The proposed MPPT tracks the MPP under different levels of solar irradiance

4. At reduced level of solar insolation, the tracking efficiency of the proposed MPPT is quite poor.

5. The Lead-Acid batteries are widely adopted in PV applications due availability in different sizes, reduced cost and robust performance.

6. Lead-Antimony battery enjoys reduced cost, wide availability, good deep charge/discharge cycle, and withstanding high temperature, whereas they suffer from the water loss and requirement for albeit high maintenance rate.

7. The proposed MPC is simple, reliable and efficient.

8. The proposed MPC has the advantages of reducing the distortion in the PV generator, battery and load currents, which limits the losses and increases the life-cycle of these components.

9. The proposed MPC has prominent advantage of producing high level DC output, which could be suitable for further AC conversion.

10. The proposed PV lighting system has the advantages of reliability, simplicity and environmental compatibility.

\section{ACKNOWLEDGMENT}

The authors are acknowledged for the Spanish Agency of International Development Cooperation (AECID) for funding this research work under A/030852/10.

\section{REFERENCES}

[1] T. J. Bialasiewicz, "Power-Electronics Systems for the Grid Integration of Renewable Energy Sources: A Survey " IEEE 
Transactions on industrial Electronics, vol. 53, p. 1002:1016, August 2006.

[2] T. J. Bialasiewicz, "Renewable Energy System with Photovoltaic Power Generators: Operation and Modeling," IEEE Transactions on industrial Electronics, vol. 55, pp. 2752-2758, July 2008.

[3] E. Endo and K. Kurokawa "Sizing procedure for photovoltaic systems " in IEEE First World Conference on Photovoltaic Energy Conversion, 1994, pp. 1196 - 1199.

[4] V. Risser and H. Post "Stand-Alone Photovoltaic Systems: A Handbook of Recommended Design Practices." Sandia PV Design Assistance Center, SAND87-7023, November 1991.

[5] J. F. Kreider and F. Kreith" Solar Energy Handbook", McGraw-Hill, 1981.

[6] M. G. Villalva; J. R. Gazoli and E. R Filho. "Comprehensive Approach to Modeling and Simulation of Photovoltaic Arrays," IEEE Transactions on power electronics, vol. 24, pp. 1198-1208, 2009.

[7] A. D. Hansen; P. Sørensen; L. H. Hansen and H. Bindner "Models for a Stand-Alone PV System", Risø-R-1219(EN) / SEC-R-12, 2000

[8] S. Hameed; R. D. Cess and J. S. Hogan; " Response of the Global Climate to Changes in Atmospheric Chemical Composition Due to Fossil Fuel Burning" Journal of Geophysical, vol. 85, 1980, pp. 75377545.

[9] IES Lighting Handbook, 8th ed., Reference and Application, Illuminating Engineering Society of North America, New York, 1993.

[10] American National Standard Practice for Roadway Lighting, ANSI/IES RP-8, Illuminating Engineering Society of North America, 1983.

[11] S. Rios; R. Castaneda and D. Veas "Harmonic distortion and power factor assessment in city street gas discharge lamps" IEEE Transaction on Power Delivery,vol. 11, pp: 1013-1020, April 1996.

[12] Reference about the street lamps in Egypt and the future trendsetter

[13] J. B. Copetti and F. Chenlo" Lead/acid batteries for photovoltaic applications: Test results and modeling" Journal of Power Sources, vol. pp. 109-118, January 1994.

[14] D. U. Sauera; M. Bächlerc; G. Boppa, W. Höheb, J. Mittermeierb, P. Sprauc, B. Willerd and M. Wollnyd" Analysis of the performance parameters of lead/acid batteries in photovoltaic systems" Journal of Power Sources, vol. 64, pp. 197-201, January-February 1997.

[15] IEEE Recommended Practice for Installation and Maintenance of Lead-Acid Batteries for Photovoltaic Application; NASI/IEEE Std 973-1987.

[16] R. R. Verderber; O. C. Morse and W. R. Alling "Harmonics from compact fluorescent lamps" IEEE Transaction on Industry Application, vol. 29, pp. 670-674, May/June 1993.

[17] Egyptian Minsitry of Electrcity and Energy" Regulation for lightings of Public avaenu and Roads" internal memorandum, April 1990.

[18] J. Dunlop" Stand-alone Photovoltiac lighting system" Florida University Engery research Centre publications, pp. 1-25, September 1998

[19] Solar direct, http://www.solardirect.com/pv/pvlist/pvlist.htm

[20] M. G. Villalva; J. R. Gazoli, and E. R. Filho, "Comprehensive Approach to Modeling and Simulation of Photovoltaic Arrays," IEEE Transactions on Power Electronics, vol. 24, pp. 1198-1208, 2009.

[21] BP

http://www.connexaenergy.com/Default.aspx?tabid=933\&CategoryID $=299 \&$ List $=0 \&$ SortField $=$ ProductName $\% 2$ cProductName $\&$ Level $=\mathrm{a} \&$ ProductID $=516$

[22] D. A. J. Rand" Vave-Regulated Lead-Acid Batteries" $1^{\text {st }}$ edition, Library of Congress, 2004.

[23] A. A. Hafez "simple and robust Maximum Power Point Tracking Algorithm for a solar cell," in World Congress on Electronics and Electrical Engineering (WCEEENG'10), 2010,pp. 240-245, April 2010.

[24] A. A. Hafez; D. Montesions and A. Sudria " Autonmoinous Cascaded PV system" Journal of Engineering Scienecs, vol. 1, pp. 243-250, November 2011

[25] T. Esram and P. L. Chapman " Comparison of Photovoltiac Array Maximum Power Point Tracking Techniques" IEEE Transactions on Energy Conversion, vol. 22, 2007.

[26] W. Dorf and R. Bishop, "Modern Control Systems", $2^{\text {nd }}$ edition Addison-Wesley, 1998. 